\title{
SÍNTESE E CARACTERIZAÇÃO DE COMPÓSITOS DE FOSFATO DE CÁLCIO E NANOFIBRAS DE CELULOSE VISANDO APLICAÇÃO NO REPARO DE TECIDOS ÓSSEOS
}

\section{SYNTHESIS AND CHARACTERIZATION OF CALCIUM PHOSPHATE AND CELLULOSE NANOFIBER COMPOSITES AIMING APPLICATION IN BONE TISSUE REPAIR}

\author{
F. T. FÉLIX ${ }^{1}$, J. P. N. MARINHO ${ }^{1}$, S. N. da SILVA $^{1}$ e D. M. de F. S. AZEVEDO ${ }^{1}$ \\ ${ }^{1}$ Centro Federal de Educação Tecnológica de Minas Gerais, Departamento de Engenharia \\ Materiais, Brasil \\ E-mail: cielle_1993@hotmail.com
}

article info

Article history:

Received 2017-09-04

Accepted 2017-11-20

Available online 2017-12-20
PAlaVRaS-CHAVE: Tecido Ósseo; Compósito; Nanofibra de Celulose; Fosfato de Cálcio Bifásico. KEYWORDS: Bone Tissue; Composite; Cellulose Nanofiber; Biphasic Calcium Phosphate.

RESUMO: O reparo fisiológico do tecido ósseo é inviável dependendo da extensão e gravidade da lesão, os aloenxertos são uma alternativa como auxílio na neoformação tecidual. Nanofibras de celulose (NFCs) $e$ fosfato de cálcio bifásico (BCP) foram utilizados na síntese e caracterização de compósitos nanoestruturados para potencial aplicação como enxerto ósseo. NFCs foram produzidas por hidrólise ácida a partir de algodão comercial com rendimento superior a 90\%, diâmetro médio de 12,75nm e índice de cristalinidade igual a $80 \%$. As amostras foram feitas nas proporções 100:0, 75:25, e 60:40 de BCP e NFC respectivamente, e sua caracterização indicou integração entre as fases, hidrofilicidade, poros na ordem de 10um e área superficial semelhante à de enxertos comerciais. A incorporação de NFC ao BCP levou a um aumento da área superficial do particulado 75:25; no entanto, sua facilidade de aglomeração provocou o efeito contrário quando adicionado em excesso no particulado 60:40.

\begin{abstract}
The physiological repair of the bone tissue is not feasible depending of the lesion extent and severity, allografts are an alternative as an aid in the tissue neoformation. Cellulose nanofibers (NFCs) and biphasic calcium phosphate $(B C P)$ were used in the synthesis and characterization of nanostructured composites for potential application as bone graft. NFCs were produced by acid hydrolysis from commercial cotton with yield greater than $90 \%$, average diameter of $12.75 \mathrm{~nm}$ ad crystallinity degree $80 \%$. The samples were made in proportions of 100:0, 75:20 and 60:40 of BCP and NFCs respectively, and their characterization indicated integration between the phases, hydrophilicity, pores in the order of $10 \mu \mathrm{m}$ and a similar surface area compared to commercial grafts. Incorporation of NFC to BCP led to an increase of the surface area in the 75:25 particulate; however, its easy agglomeration caused the opposite effect when added in excess in 60:40 particulate.
\end{abstract}

\section{INTRODUÇÃO}

A qualidade de vida de um indivíduo está diretamente ligada à saúde dos ossos, porque esse tecido atua na sustentação de tecidos moles e musculatura, locomoção do corpo, 
proteção de órgãos vitais, armazenamento de triglicérides, hematopoiese e homeostase mineral (TORTORA; DERRICKSO, 2012). Quando lesionados, os ossos possuem uma enorme capacidade de regeneração. Entretanto, a eficácia do reparo depende da extensão da lesão. Peterson (2004) estima que a separação máxima entre duas extremidades ósseas para que as características do tecido sejam mantidas após o reparo fisiológico é aproximadamente 1 milímetro. Caso contrário, as extremidades não se unirão ou ocorrerá uma depressão na área reparada, podendo levar a defeitos funcionais e/ou estéticos ao indivíduo. Nesse caso faz-se necessário o uso de enxertos ósseos que auxiliem a neoformação tecidual (NOORI et al., 2017; CHEN et al., 2016).

Enxertos autógenos, cujo doador é o próprio paciente, são ideais devido à elevada imunocompatibilidade. No entanto, são limitados quanto a disponibilidade óssea e aumento dos riscos operatórios e pós-operatórios no paciente (CHEN et al., 2016; NOORI et al., 2017). A engenharia de tecidos tem avançado, portanto, em pesquisas de enxertos aloplásticos, substitutos ósseos sintéticos com possibilidade de produção em escala industrial, mas que muitas vezes necessitam de tratamentos para elevação do grau de osteogenicidade e osteocondutividade (STEIN, 2009).

Um constructo ideal para engenharia de tecidos, denominado scaffold, além de ser um suporte apropriado para regeneração tecidual deve conter também uma fonte de células, fatores de crescimento e de diferenciação. Dentre as características desejáveis de um scaffold para reconstrução de tecido ósseo pode-se destacar: biocompatibilidade, biodegradabilidade, osteocondutividade, propriedades mecânicas adequadas, facilidade de produção, manuseio e esterilização (SEO et al., 2015; NOORI et al., 2017). Uma matriz porosa com poros interconectados é importante para que ocorra vascularização e a invasão celular no biomaterial, interferindo assim na organização do tecido formado. Bose et al. (2012) relatam que poros com $100 \mu \mathrm{m}$ de diâmetro já seriam suficientes para a vascularização do tecido, mas insatisfatórios para a infiltração celular. Seo et al., (2015) descrevem para os tecidos ósseos esponjosos uma porosidade entre $50 \%$ e $90 \%$ e poros com diâmetro de aproximadamente 1 $\mathrm{mm}$. Desta forma, enxertos aloplásticos com capacidade osteogênica devem apresentar porosidade acima de $50 \%$ e poros com diâmetro superior a $100 \mu \mathrm{m}$.

Entre os biomateriais que se destacam nessa área, encontram-se os fosfatos de cálcio, como a hidroxiapatita e o trifosfato de cálcio ( $\beta$-TCP). Esses materiais são quimicamente e biologicamente similares à fase mineral do osso nativo. São, portanto, biocompatíveis, osteocondutivos e bioativos, se ligando facilmente ao tecido adjacente. Entretanto, sua fragilidade torna impossível o seu uso isoladamente como um substituto ósseo temporário. Em contrapartida, a ductilidade e resistência ao impacto dos polímeros contrasta com as limitações dos cerâmicos para essa aplicação (YAN et al., 2017). Ambas as classes de materiais, cerâmicos e poliméricos, são por isso amplamente estudados na construção de scaffolds compósitos. Isto é, materiais multifásicos em que os constituintes de cada fase imprimem novas propriedades ao material formado, baseadas em suas características individuais (CHEN et al., 2016).

Entre os polímeros naturais, a celulose é extremamente abundante podendo ser encontrada em plantas, na parede celular de bactérias e em alguns animais marinhos (NAKASHIMA et al., 2010), e pode ser sintetizada por fungos. A celulose é um 
homopolímero de cadeia rígida com repetições celoboise, formadas por duas moléculas de glicose esterificadas por ligações $\beta-1,4$ glicosídicas (SOLOMONS, 2002). Devido a notáveis propriedades físicas como elevada resistência mecânica, biodegradabilidade e baixa toxicidade, a nanocelulose tem sido amplamente estudada como material biomimético (LIN; DUFRESNE, 2014). Rao e colaboradores (2017) reforça ainda que a baixa densidade e elevada razão de aspecto desses materiais os colocam como promissores materiais de reforço em biocompósitos.

Compósitos são materiais cuja fase de maior proporção (fase contínua) envolve uma fase dispersa (reforço), o aglutinando, estabilizando e protegendo. A matriz suporta maior parte da carga aplicada e confere acabamento. O reforço absorve parte das cargas aplicadas, e restringe o movimento da matriz melhorando a resistência mecânica (FLAMÍNIO; PARDINI, 2006). Dois exemplos são os trabalhos de Salama (2015) e Yan et al. (2017). Salama (2015) produziu compósitos com poli(ácido acrílico), celulose e fosfatos de cálcio para aplicação em regeneração óssea e Yan et al. (2017), com o mesmo objetivo, produziu compósitos de nanohidroxiapatita reforçados com poly(L-acido lático). Ambos obtiveram resultados promissores, incluindo biocompatibilidade in vivo.

\section{2 Fosfato de Cálcio Bifásico (BCP)}

Fosfatos de cálcio são biocompatíveis devido a composição semelhante à fase mineral de ossos, dentes e tecidos calcificados. Esses materiais são solúveis em água, possibilitando a troca de íons $\mathrm{Ca}^{2+}$ e $\mathrm{PO}_{4}{ }^{3-}$ com o meio biológico, sendo assim bioativos, e facilitadores do crescimento e da regeneração óssea (GUASTALDI; APARECIDA, 2010). Em scaffolds, as taxas de degradação do material e de proliferação óssea devem ser equivalentes para que o tecido em construção ocupe o espaço anteriormente ocupado pelo biomaterial sintético. Pode-se dizer que a solubilidade, e consequente taxa de degradação dos fosfatos de cálcio decresce com o aumento da razão $\mathrm{Ca} / \mathrm{P}$. A hidroxiapatita (HA), de fórmula química $\mathrm{Ca}_{10}\left(\mathrm{PO}_{4}\right)_{6}(\mathrm{OH})_{2}$, possui taxa de degradação muito lenta em relação à proliferação óssea. $\mathrm{O}$ fosfato tricálcico $(\beta-\mathrm{TCP}), \mathrm{Ca}_{3}\left(\mathrm{PO}_{4}\right)_{2}$, em contrapartida, degrada-se rapidamente (ERGUN, et al., 2011; YAN et al., 2017). Por isso, nos últimos trinta anos tem sido usual a produção de fosfatos de cálcio bifásicos, isto é, que apresentem HA e $\beta$-TCP em sua composição, visando controlar a taxa de degradação (GARAI; SINHA, 2016).

\subsection{Nanofibras de Celulose (NFCs)}

A celulose é um polímero natural, renovável e biodegradável que pode ser obtido de plantas, ou sintetizado por fungos e bactérias. Nos sistemas biológicos microfibrilas cristalinas são envolvidas por uma matriz amorfa de lignina e hemicelulose. Essas regiões amorfas agem como deformações estruturais que, quando submetidas ao ataque ácido, são mais susceptíveis à ruptura transversal das fibras, produzindo nanofibras no formato de agulhas. Quando em escala nanométrica, a celulose possui excepcionais características como: elevada razão de aspecto, elevada resistência mecânica (o módulo de Young pode chegar até $138 \mathrm{GPa})$ e baixa densidade $\left(1,5 \mathrm{~g} / \mathrm{cm}^{3}\right)$; propriedades que a habilitam como reforço em nanocompósitos mais resistentes e leves (CHEN et al., 2016; MORAES et al., 2016).

O algodão comercial é uma excelente fonte de NFCs por ser constituído de microfibras 
de celulose em quase sua totalidade. Entretanto, para obtenção desse material em escala nanométrica faz-se necessário que o mesmo seja hidrolisado com ácido (NASCIMENTO et al., 2015; MORAES et al., 2016). A hidrólise ácida das microfibras é comumente realizada com os ácidos sulfúrico e clorídrico. O ácido sulfúrico mantém a suspensão estável devido à incorporação de grupos sulfato à celulose, entretanto, essa incorporação exerce efeito catalítico nas reações de degradação térmica. A substituição de hidroxilas por grupos sulfatos também diminui a energia de ativação para degradação das cadeias. $\mathrm{O}$ uso de ácido clorídrico, por sua vez, aumenta a estabilidade térmica, mas repetidas lavagens com água retiram os cloretos e a força de repulsão eletrostática que ele gera, permitindo a formação de agregados. Fatores como tempo e temperatura de reação, vigorosidade da agitação mecânica e concentração dos ácidos influenciam nas propriedades e características das nanofibras de celulose obtidas (TEIXEIRA et al., 2010; TAIPINA et al., 2012; CHEN et al., 2016).

Diante do exposto e visando a produção de um material poroso para possível recuperação tecidual óssea, foram produzidos e caracterizados físico-quimicamente compósitos formados por fosfato de cálcio bifásico reforçados com nanofibras de celulose em diferentes proporções.

\section{MÉTODOS}

\subsection{Síntese do Fosfato de Cálcio Bifásico (BCP)}

A síntese do BCP foi realizada a partir da dissolução de hidróxido de cálcio $\left(\mathrm{Ca}(\mathrm{OH})_{2}\right)$ e fosfato de cálcio monobásico hidratado $\left(\mathrm{Ca}\left(\mathrm{H}_{2} \mathrm{PO}_{4}\right)_{2} \cdot \mathrm{H}_{2} \mathrm{O}\right)$, em água deionizada, conforme a reação de precipitação descrita na equação 1 .

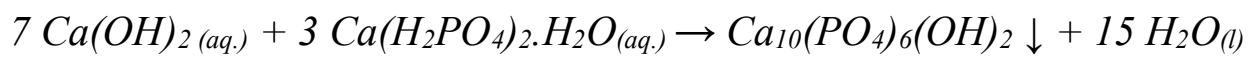

A suspensão foi mantida em repouso por 24 horas para a decantação, o sobrenadante foi descartado e o precipitado seco a $150^{\circ} \mathrm{C}$ por 120 horas. Posteriormente, o material foi sinterizado a $900^{\circ} \mathrm{C}$ durante 4 horas, triturado no gral e peneirado a fim de se obter uma granulometria entre 38 e $53 \mu \mathrm{m}$.

\subsection{Caracterização do BCP}

A Microscopia Eletrônica de Varredura (MEV) foi realizada no microscópio Shimadzu, modelo SSX-550, acoplado a análise de composição química por espectroscopia de dispersão de raios-X (EDS). A análise granulométrica foi realizada pelo método de espalhamento de luz em um granulômetro a laser, Cilas 1090. Para análise da cristalinidade do material e constituição das fases, foi feita a difração de raios-X (DRX) utilizando o difratômetro Shimadzu XRD-7000, utilizando um tubo de radiação de $\mathrm{CuK \alpha}(\lambda=1,5418 \AA, 40 \mathrm{kV}, 30 \mathrm{~mA})$. A amostras foram analisadas em ângulos de varredura de 10 a $80^{\circ}(2 \theta)$, num passo de $0,02^{\circ}$, com intensidades registradas a cada 40 s. 


\subsection{Síntese de NFCs}

As NFCs foram obtidas por meio de hidrólise ácida como previamente reportado por Taipina (2012) com pequenas alterações. Uma solução ácida foi preparada com concentração de $2,2 \mathrm{~mol} / \mathrm{L}$ de $\mathrm{HCl}$ e $3,62 \mathrm{~mol} / \mathrm{L}$ de $\mathrm{H}_{2} \mathrm{SO}_{4}$, mantida a $65^{\circ} \mathrm{C}$, e vertida sob uma amostra de algodão comercial seguindo a proporção de $1 \mathrm{~g}$ de algodão para $33,3 \mathrm{~mL}$ de solução. A mistura foi mantida sob agitação magnética a $65^{\circ} \mathrm{C}$ por 75 minutos, e então neutralizada com $\mathrm{NaOH}$ até obtenção de $\mathrm{pH}$ neutro. Após as NFCs decantarem, o sobrenadante foi retirado e a amostra foi lavada com água destilada e, posteriormente, seca em estufa a $60^{\circ} \mathrm{C}$ por 24 horas. O gral foi utilizado para obtenção do pó desejado.

\subsection{Caracterização das NFCs}

Análises de microscopia eletrônica de transmissão (MET) foram realizadas no equipamento Tecnai G2-20 - SuperTwin FEI-200Kv, operado a $200 \mathrm{kV}$ com tensão variável de $60 \mathrm{kV}$, resolução de linha de $0,10 \mathrm{~nm}$ e de ponto de $0,24 \mathrm{~nm}$. As amostras submetidas à microscopia eletrônica foram previamente preparadas com solução contraste de $2 \%$ de acetato de uranila, conforme procedimento descrito por Teixeira et al. (2010). A composição química das NFCs foi obtida por meio de espectroscopia de infravermelho com transformada de Fourrier (FTIR) utilizando o equipamento Nicolet Thermo Scientific 380 com cristal de seleneto de zinco e faixa espectral variando de 400 a $4000 \mathrm{~cm}^{-1}$ com resolução de $4 \mathrm{~cm}^{-1}$. A cristalinidade do material foi avaliada a partir das análises de DRX utilizando os parâmetros anteriormente descritos. $\mathrm{O}$ índice de cristalinidade $\left(\mathrm{I}_{\mathrm{c}}\right)$ foi calculado utilizando a equação 2 ,

$$
I_{c}=\left(I_{\text {cristalino }}-I_{\text {amorfo }}\right) /\left(I_{\text {cristalino }} x\right. \text { 100) }
$$

em que $\mathrm{I}_{\text {cristalino }}$ corresponde a intensidade da fase cristalina $\left(2 \theta \sim 22,6^{\circ}\right)$ e $\mathrm{I}_{\text {amorfo }}$ corresponde a intensidade da fase amorfa $\left(2 \theta \sim 18^{\circ}\right)$ em relação à linha de base. (MARTINS et al., 2011). A análise termogravimétrica (TGA) foi realizada no equipamento SII EXSTAR, modelo TG/DTA 7200 em atmosfera dinâmica de nitrogênio com vazão de $90 \mathrm{~mL}^{-\mathrm{mim}^{-1}}$ e taxa de aquecimento de $10^{\circ} \mathrm{C} \cdot \mathrm{min}^{-1}$, na temperatura compreendida entre $10^{\circ} \mathrm{C} \mathrm{a} 900^{\circ} \mathrm{C}$.

\subsection{Obtenção dos Compósitos}

Três amostras foram preparadas com diferentes proporções de BCP e NFC - 100:0 (BCP100), 75:25 (BCP75) e 60:40 (BCP60). Cada amostra foi hidratada e agitada vigorosamente por 5 minutos com $0,01 \%(\mathrm{~m} / \mathrm{m})$ de surfactante Triton $^{\mathrm{TM}}-\mathrm{X}-100$. Posteriormente foram depositadas em um recipiente de alumínio e levadas à estufa por 60 minutos a $60^{\circ} \mathrm{C}$. Parte das amostras foi submetida a uma pressão de $100 \mathrm{kPa}$ por 1 minuto para formação de pastilhas. As espumas e pastilhas foram submetidas a tratamento térmico: resfriadas a $-18^{\circ} \mathrm{C}$ por 10 minutos e então colocadas em estufa pré-aquecida a $168^{\circ} \mathrm{C}$ e mantidas por 3 horas. 


\subsection{Caracterização dos Compósitos}

As análises de microscopia eletrônica de varredura e espectroscopia de infravermelho com transformada de Fourrier foram realizadas conforme parâmetros anteriormente descritos. Curvas isotermas de Brunauer, Emmett e Teller (BET) foram obtidas em equipamento da marca Nova, modelo 2200 com coleta de 30 pontos. Para medida do ângulo de contato, foi utilizado o equipamento da marca Kruss, modelo DAS100. Gotas de água destilada de diâmetro $30 \mu \mathrm{L}$ com velocidade de descida de $10 \mu \mathrm{L}$ por segundo caíram sob as amostras para obtenção da imagem e medida do ângulo de contato.

\section{RESULTADOS}

\subsection{Caracterização do BCP}

A morfologia das partículas de $\mathrm{BCP}$ encontra-se demonstrada na figura 1. As micrografias mostram que as partículas formam aglomerados granulares de tendência esférica, com superfície rugosa, além da presença de micro e macroporos.
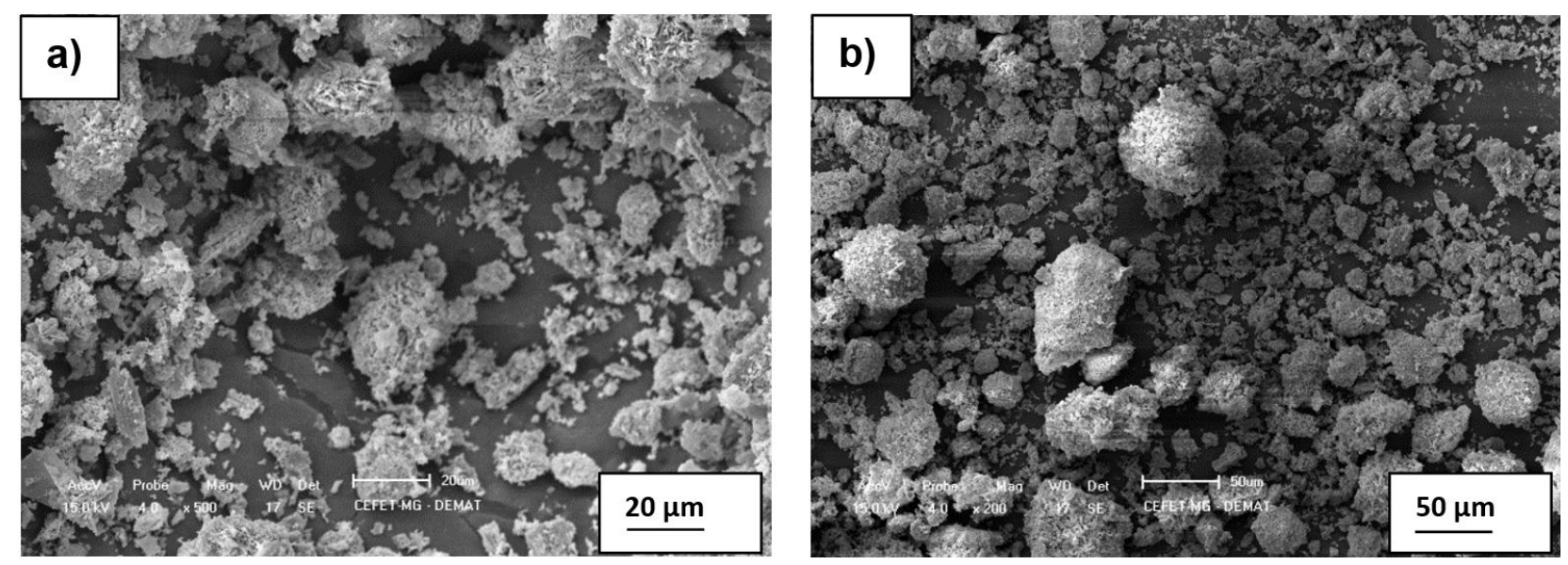

Figura 1 - MEV das partículas de BCP

A distribuição granulométrica das partículas está representada na figura 2. O tamanho médio é $31,36 \mu \mathrm{m}$. 


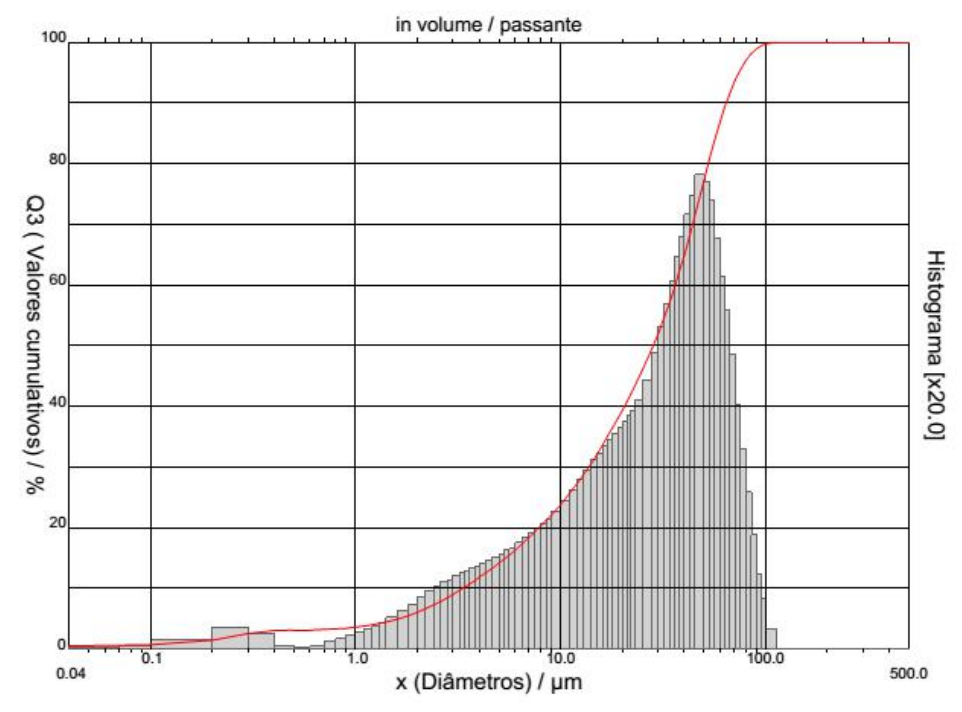

Figura 2 - Gráfico da distribuição granulométrica do BCP

O difratograma das micropartículas de BCP obtido no ensaio de DRX é apresentado na figura 3. Nele é possível identificar picos cristalográficos pertencentes a hidroxiapatita, e picos característicos de $\beta$-TCP. Percebe-se, portanto, que a rota de produção utilizada levou à formação de um fosfato de cálcio bifásico (NIKČEVIĆ et al., 2006; FRANÇA et al., 2014; UNABIA et al., 2014). A intensidade dos picos indica alta cristalinidade das fases, o que justifica o tamanho relativamente grande dos cristais (ALBAYRAK, 2016; VILLALÁ, 2017; RAMEZANI et al., 2017).

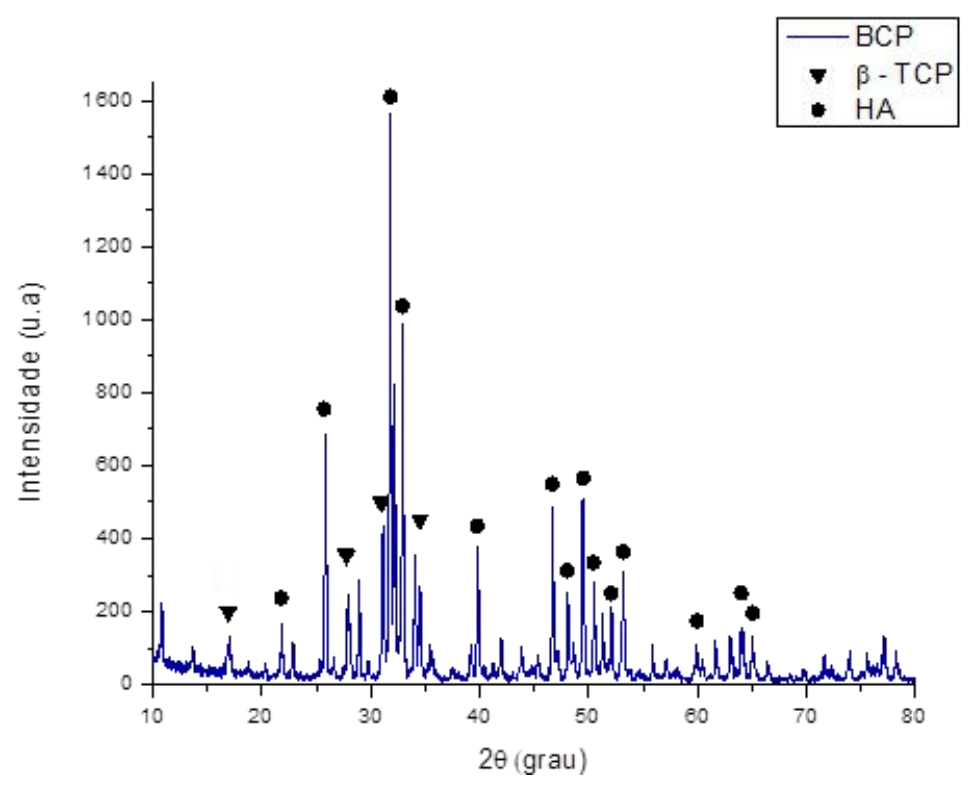

Figura $3-$ DRX do BCP 


\subsection{Produção e Caracterização das Nanofibras de Celulose}

As NFCs produzidas por hidrólise ácida originaram uma suspensão estável com aspecto branco, leitoso e homogêneo, conforme demonstrado na figura 4a. Após a neutralização com hidróxido de sódio a massa de NFC hidratada decantou e o sobrenadante apresentou aspecto límpido. A parte decantada apresentou aspecto pastoso e uma massa cerca de quatro vezes maior que a massa seca de algodão introduzida na mistura. Ao final do processo de secagem e cominuição, obteve-se um pó branco, fino e solto, apresentado na figura 4b. O rendimento da produção das NFCs foi de aproximadamente $91,5 \%$.

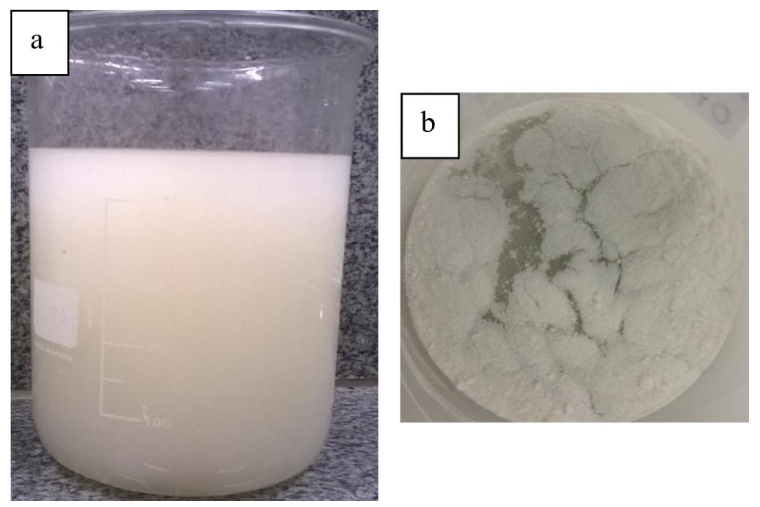

Figura 4 - a) Suspensão de NFC antes da neutralização, e (b) pó obtido no final do processo, após secagem e cominuição dos grãos formados

As imagens obtidas na microscopia eletrônica de transmissão, figura 5, indicaram que a estrutura da NFC é nanométrica, em formato de agulha, e que as nanofibras encontram-se aglomeradas em feixes. O diâmetro médio observado foi de $12,75 \mathrm{~nm}$.

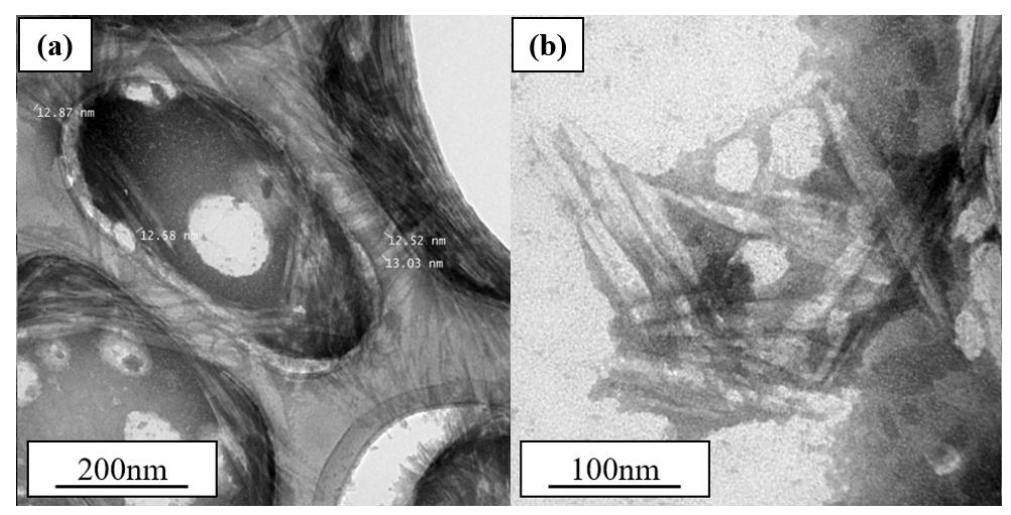

Figura 5 - MET das NFCs 
A figura 6 apresenta os difratogramas de raios- $\mathrm{X}$ das amostras de algodão comercial $\mathrm{e}$

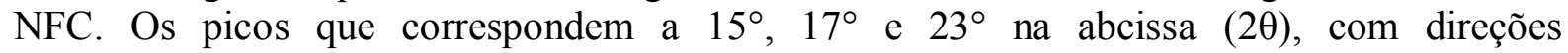
cristalográficas (101), (10-1) e (002) respectivamente, indicam a presença de celulose tipo I, presente em ambas as amostras. $\mathrm{O}$ pico em $34,5^{\circ}$ referente ao plano cristalográfico (040) é característico apenas de NFC (TEIXEIRA et al., 2010; TAIPINA, 2012).

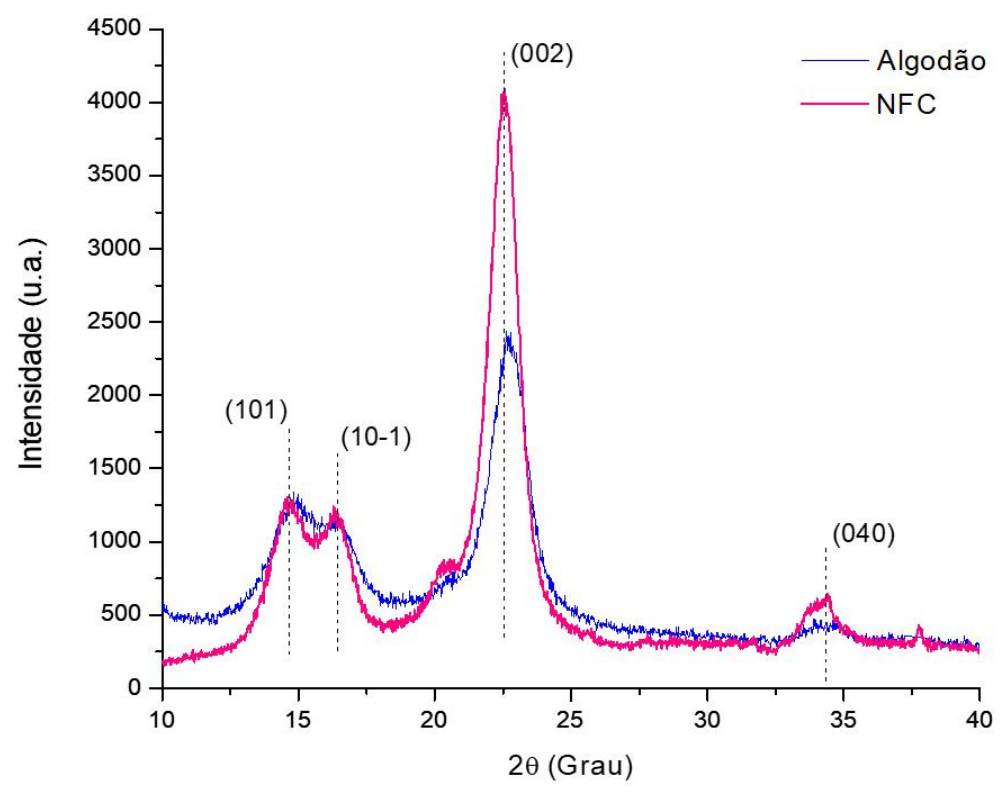

Figura 6 - Difratograma de raios-X das amostras de algodão e NFC

Uma análise comparativa dos difratogramas mostra que a intensidade dos picos sofreu alteração, resultando em uma maior cristalinidade das fibras após a hidrólise ácida. Utilizando a equação 2 obtém-se que o índice de cristalinidade das fibras aumentou de $68 \%$ para $80 \%$.

Os espectros de infravermelho do algodão comercial e das NFCs encontram-se apresentados na Figura 7. Nos espectros pode-se observar picos em $3331,2 \mathrm{~cm}^{-1}$ e $3333,1 \mathrm{~cm}^{-1}$ característicos dos grupos hidroxila da celulose e da água de hidratação das fibras. Os picos a $2897,2 \mathrm{~cm}^{-1}$ e $2902,9 \mathrm{~cm}^{-1}$ são característicos da vibração de estiramento, vibração simétrica e assimétrica de $\mathrm{CH}$ alifáticos presentes. As bandas de $1632,8 \mathrm{~cm}^{-1}$ e $1640,5 \mathrm{~cm}^{-1}$ podem ser obtidas pela presença de água nas fibras ou reações de oxidação. As bandas em $1429,3 \mathrm{~cm}^{-1} \mathrm{e}$ $1427,3 \mathrm{~cm}^{-1}$ caracterizam deformação angular de $\mathrm{C}-\mathrm{H}$. O pico no comprimento de onda $1314,5 \mathrm{~cm}^{-1}$ foi equivalente em ambas as amostras, e é formado devido a presença de vibrações entre grupos $\mathrm{C}-\mathrm{O}$, tal vibração ocorre em estiramentos de anéis. Os picos coincidentes a $1030,0 \mathrm{~cm}^{-1}$ estão relacionados a estiramentos $\mathrm{CO}$ e $\mathrm{OH}$ na celulose. Por fim, os picos $903,7 \mathrm{~cm}^{-1}$ e $907,5 \mathrm{~cm}^{-1}$ são formados devido a ligações $\beta$ glicosídicas entre os monossacarídeos. As bandas encontradas são típicas da celulose, como descrito previamente por Taipina (2012), Sá et al. (2015) e Nascimento et al. (2016). Além dos picos descritos, na 
amostra de NFCs observa-se um pico em $1730,0 \mathrm{~cm}^{-1}$ que não está presente na amostra de algodão comercial.

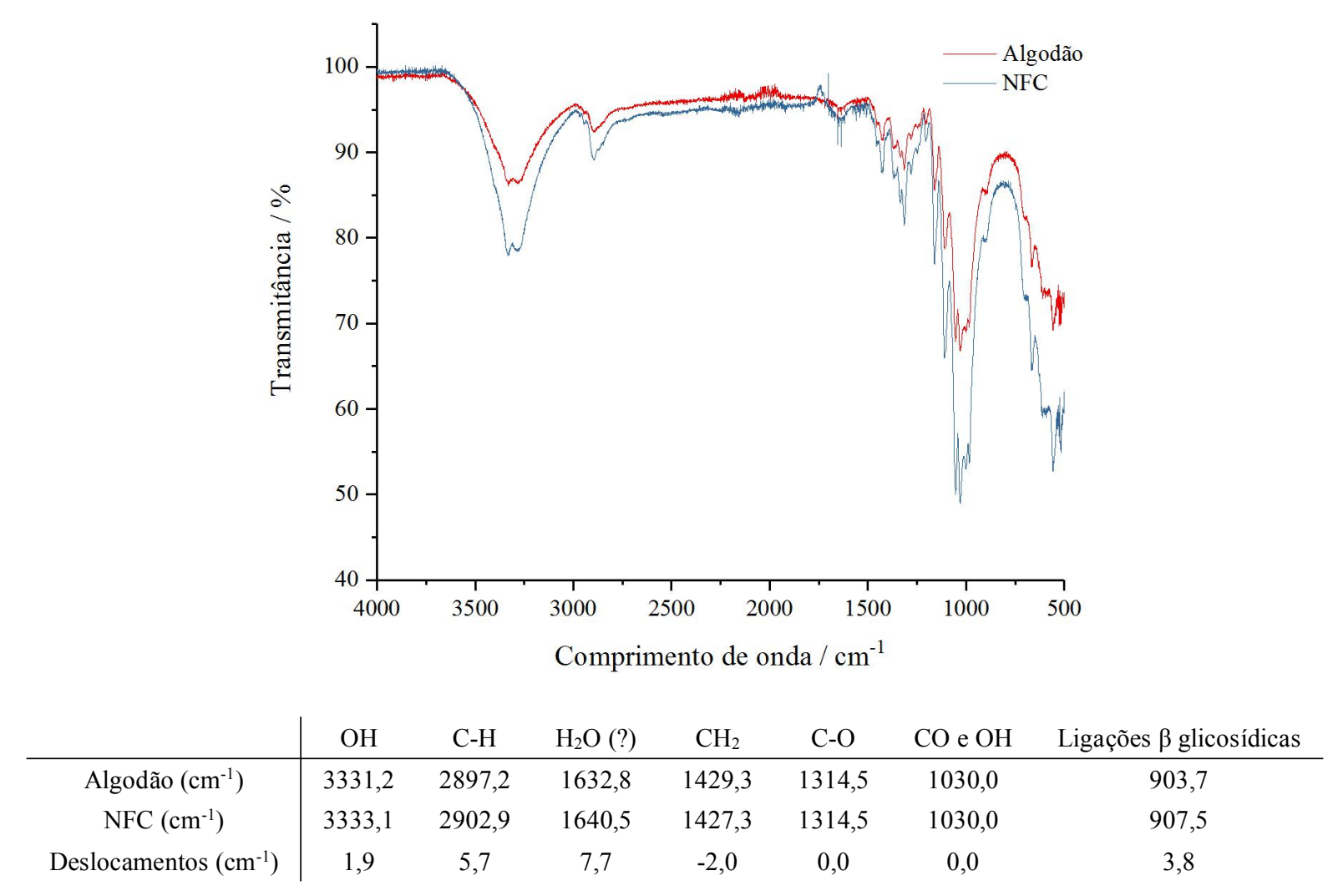

Figura 7 - FTIR das amostras de algodão e NFC

As curvas de TGA das fibras de algodão comercial e das NFCs apresentadas na figura 8, mostram uma pequena perda de massa inicial entre 50 e $100^{\circ} \mathrm{C}$, que corresponde à vaporização da água em ambas as amostras. A temperatura máxima de degradação do algodão foi $325^{\circ} \mathrm{C}$, enquanto que a da NFC foi de $300^{\circ} \mathrm{C}$. A partir de $350^{\circ} \mathrm{C}$ ocorre o terceiro evento de perda de massa referente à $\mathrm{NFC}$ e a $364^{\circ} \mathrm{C}$ referente ao algodão, que pode ser atribuído à degradação da celulose em produtos de baixo peso molecular (MARTINS et al., 2011; MARIANO et al., 2016). 


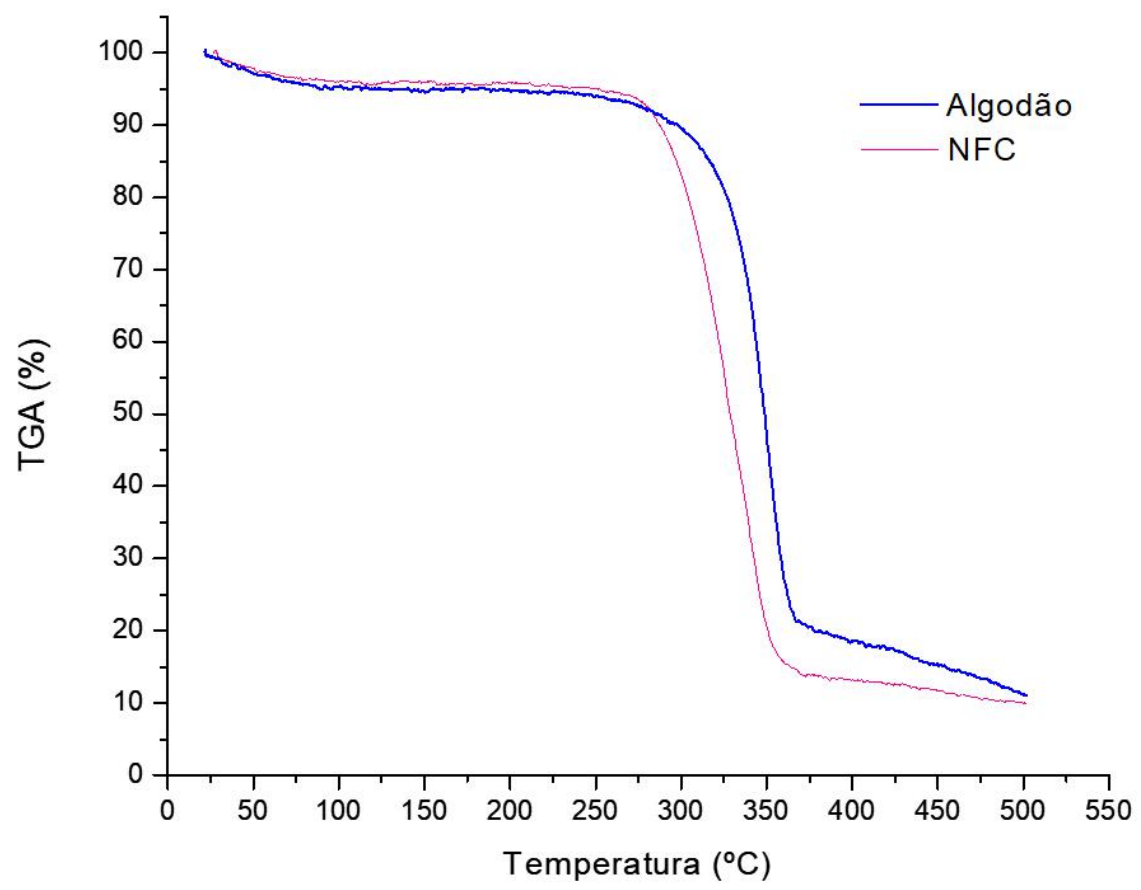

Figura 8 - TGA das amostras de algodão e NFC

\subsection{Produção e Caracterização dos Compósitos}

Após misturar as quantidades previamente determinadas de BCP, NFC, surfactante e água, a formação de bolhas estabilizadas durante o primeiro episódio de aquecimento pode ser visualizada nos painéis (a), (b) e (c) da figura 8. As pastilhas formadas encontram-se apresentadas nos painéis (d), (e) e (f). As demais imagens referem-se às amostras após o tratamento térmico: (g), (h) e (i) das partículas formadas a partir da espuma e (j), (k) e (l) das pastilhas formadas após a prensagem. Percebe-se que as amostras mudaram de tonalidade após serem submetidas ao tratamento térmico e aquelas com maior teor de NFC foram mais resistentes ao serem quebradas com as mãos. 


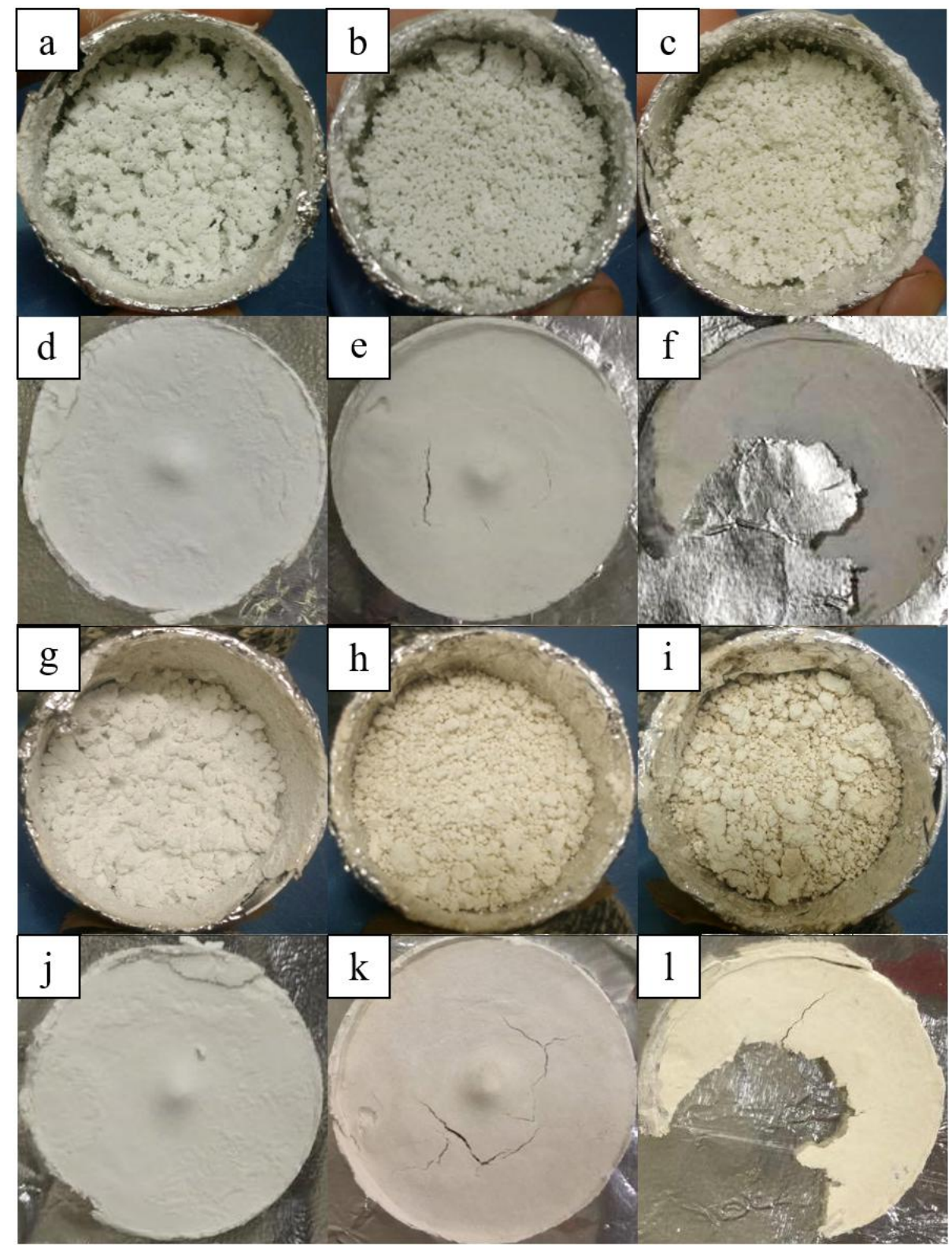

Figura 8 - Partículas e pastilhas de BCP100 ( $1^{\mathrm{a}}$ coluna), BCP75 ( $2^{\mathrm{a}}$ coluna) e BCP60 ( $3^{\mathrm{a}}$ coluna).

A micrografia de varredura dos compósitos é apresentada na Figura 9. A superfície do BCP100 apresentou-se irregular e amorfa, muito semelhante à micrografia do BCP puro visualizada na Figura 1. As amostras de BCP75 e BCP60 formaram partículas esféricas com tamanho superior a $200 \mu \mathrm{m}$. Pode-se notar também a presença de poros micrométricos e superfície bastante irregular. As setas vermelhas indicam substâncias que se assemelham a sais presentes na amostra, entretanto, não foram identificados nas análises de FTIR. 


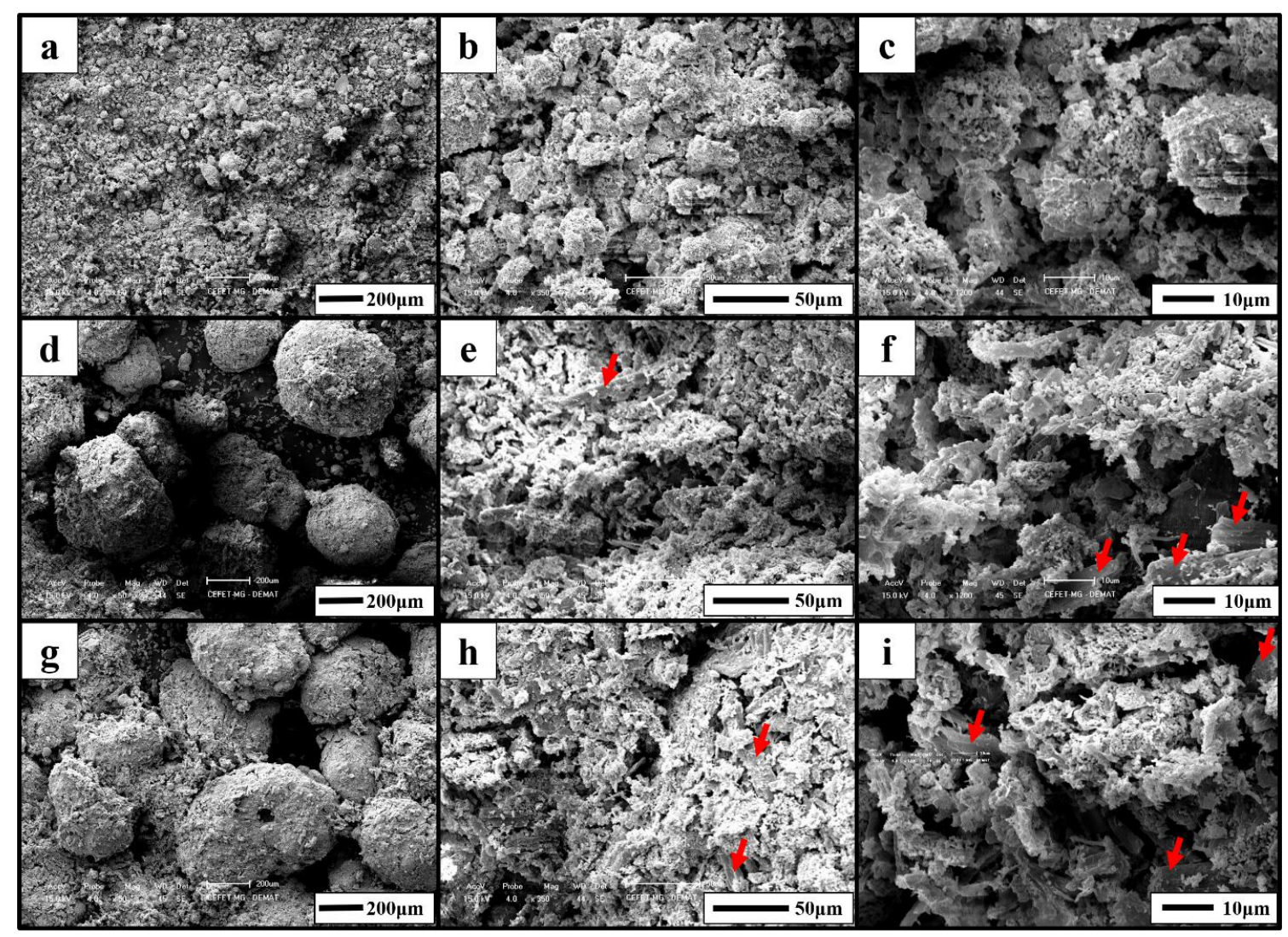

Figura 9 - Amostras (a), (b), (c) BCP100; (d), (e), (f) BCP75; (g), (h), (i) BCP60. Em cada linha encontram-se apresentados em sequência os aumentos 50x, 350x e 1200x.

A figura 10 apresenta o espectro de infravermelho comparativo dos compósitos, BPC100 e NCFs. Para a amostra BPC100 observa-se picos em $3574,3 \mathrm{~cm}^{-1}$ e $628,8 \mathrm{~cm}^{-1}$ correspondentes à hidroxila. Já os picos em $1085,0 \mathrm{~cm}^{-1}, 1022,0 \mathrm{~cm}^{-1}, 962,5 \mathrm{~cm}^{-1}, 597,9 \mathrm{~cm}^{-1} \mathrm{e}$ $559,1 \mathrm{~cm}^{-1}$ são indicativos da presença de $\mathrm{PO}_{4}{ }^{3-}$. Para as amostras BCP75 e BCP60 as duas últimas bandas identificadas, no entanto, não podem ser atribuídas apenas ao $\mathrm{CO}$ e $\mathrm{OH}$ e ligações $\beta$ glicosídicas porque se sobrepõem às bandas do $\mathrm{PO}_{4}{ }^{3-}$ presentes no $\mathrm{BCP}$ (GARAI; SINHA, 2017). Nos compósitos, as bandas características das nanofibras de celulose são identificadas com pequenos deslocamentos em relação ao espectro da NFC pura, indicando boa interação entre as fases constituintes. Adicionalmente percebe-se um aumento da intensidade dos picos referentes às NFCs à medida em que se aumenta a proporção desse material nos compósitos. 


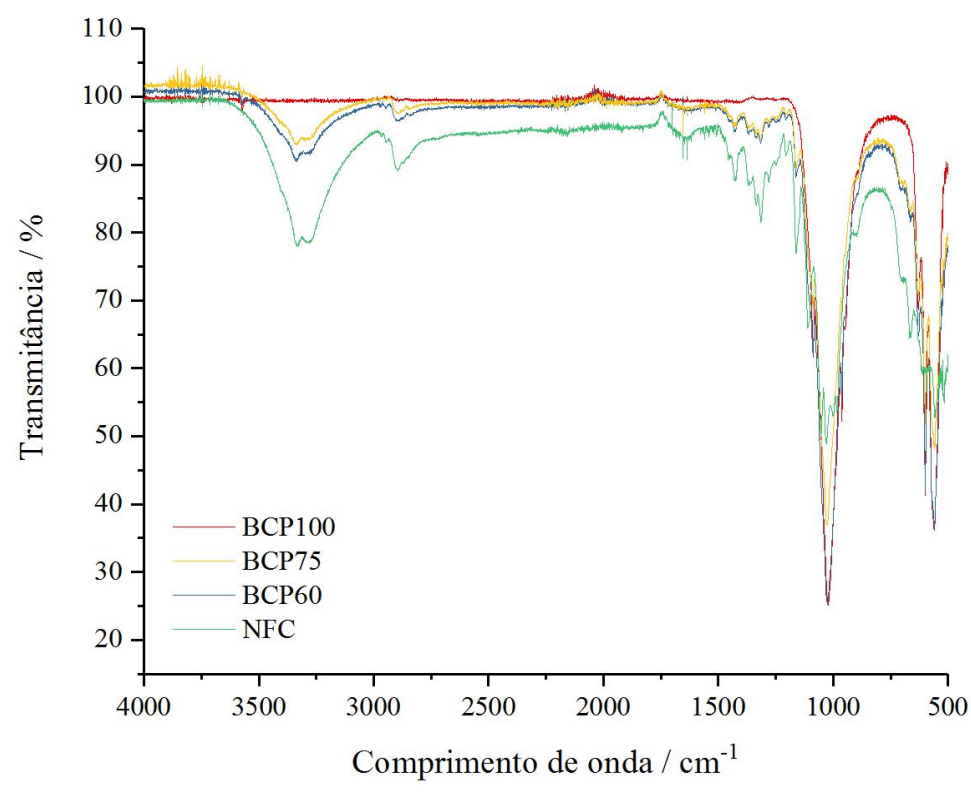

\begin{tabular}{l|cllllll}
\multirow{2}{*}{ BCP100 } & $\mathrm{PO}_{4}{ }^{3-}$ & $\mathrm{PO}_{4}{ }^{3-}$ & $\mathrm{OH}$ & $\mathrm{PO}_{4}{ }^{3-}$ & $\mathrm{PO}_{4}{ }^{3-}$ & $\mathrm{PO}_{4}{ }^{3-}$ & $\mathrm{OH}$ \\
\cline { 2 - 7 } & 559,1 & 597,9 & 628,8 & 962,5 & 1022,0 & 1085,0 & 3574,3 \\
\hline \multirow{3}{*}{ NFC $\left(\mathrm{cm}^{-1}\right)$} & $\mathrm{OH}$ & $\mathrm{C}-\mathrm{H}$ & $\mathrm{H}_{2} \mathrm{O}(?)$ & $\mathrm{CH}_{2}$ & $\mathrm{C}-\mathrm{O}$ & $\mathrm{CO}$ e OH (?) & Ligações $\beta$ glicosídicas \\
\cline { 2 - 7 } BCP75 $\left(\mathrm{cm}^{-1}\right)$ & 3333,1 & 2902,9 & 1640,5 & 1427,3 & 1314,5 & 1030,0 & 907,5 \\
BCP60 $\left(\mathrm{cm}^{-1}\right)$ & 3335,0 & 2893,0 & 1646,0 & 1419,6 & 1314,5 & 1026,1 & 559,0 \\
\hline
\end{tabular}

Figura 10 - FTIR dos compósitos, BCP e NFC

A área superficial calculada através do BET para as amostras BCP100, BCP75 e BCP60 foram respectivamente $1,553 \mathrm{~m}^{2} / \mathrm{g}, 2,451 \mathrm{~m}^{2} / \mathrm{g}$ e $0,196 \mathrm{~m}^{2} / \mathrm{g}$. Além disso, as pastilhas apresentaram caráter hiperhidrofílico, não sendo possível sequer capturar a imagem da gota sob as amostras porque essa foi rapidamente absorvida.

\section{DISCUSSÃO}

A caracterização físico-química do $\mathrm{BCP}$ indica que o material é formado por partículas micrométricas com macro e microporos, sendo constituído predominantemente pelas fases HA e $\beta$-TCP. Os resultados obtidos sugerem que a rota de produção por precipitação é um método eficiente de obtenção desse fosfato de cálcio.

As nanofibras de celulose produzidas apresentaram morfologia, diâmetro e cristalinidade semelhantes às nanofibras obtidas previamente por TEIXEIRA et al. (2010) e TAIPINA (2012). Além disso, o aumento da cristalinidade observado nas NFCs sugere que houve remoção das porções amorfas presentes nas microfibras do algodão indicando que o processo de hidrólise ácida seguida de neutralização é eficaz para a produção das NFCs. Todavia, as NFCs apresentaram-se aglomeradas, como pôde ser observado nas análises de 
microscopia eletrônica de transmissão. A aglomeração desse material provavelmente está relacionada com as etapas de lavagem durante a neutralização que retiram os grupos sulfatos, responsáveis pela repulsão elétrica entre as cadeias poliméricas. O material resultante, repleto de hidroxilas é facilmente aglomerado devido as suas interações de hidrogênio. A elevada aglomeração das NFCs é amplamente relatada na literatura (TEIXEIRA et al., 2010; TAIPINA et al., 2012; CHEN et al., 2016) e é um desafio para a utilização desse material como agente de reforço em matrizes, uma vez que a aglomeração reduz a área superficial de interação com a matriz além de criar pontos de fragilidade no compósito. Diversos trabalhos sugerem que sejam feitas modificações químicas nas NFCs para reduzir a aglomeração e melhorar as propriedades dos compósitos formados (TEIXEIRA et al., 2010).

As análises de espectroscopia de infravermelho indicam que a hidrólise ácida não alterou substancialmente os grupos químicos presentes no algodão comercial, entretanto, foi observado um pico em $1730,0 \mathrm{~cm}^{-1}$ presente apenas nas nanofibras de celulose. Fan et al. (2012) e Lojelsk et al. (2014) sugerem que um pico nessa região do espectro pode ocorrer devido a um processo oxidativo da celulose durante tratamento térmico. No presente trabalho a temperatura utilizada para secar as nanofibras foi de $60^{\circ} \mathrm{C}$, e de acordo com as análises termogravimétricas, nessa faixa de temperatura não há nenhum indício de processo degradativo. Desta forma, pode-se supor que o pico em $1730,0 \mathrm{~cm}^{-1}$ não se relacione com eventos de modificação química no material, mas sim com a presença de sais provenientes do processo de neutralização. Essa suposição não pôde ser confirmada porque os picos de absorbância do sulfato de sódio se sobrepõe a outros já expressos e o cloreto de sódio é transparente à radiação infravermelha (AZHA.PERIASAMY et al., 2009). Conclui-se, portanto, que outras técnicas de caracterização, como espectroscopia de RAMAN, devem ser utilizadas para investigar a presença de contaminantes na amostra.

A análise termogravimétrica mostra ainda uma redução na temperatura de degradação nas NFCs que pode ser atribuída às menores dimensões desse material em comparação com as fibras macroscópicas originais. $\mathrm{O}$ aumento em sua área superficial gera uma maior exposição ao calor. Sugere-se também que grupos sulfato residuais possam ter reduzido a temperatura de degradação da celulose, por exercer um efeito catalítico (MORAIS et al., 2013).

Os resultados da hidrólise ácida do algodão comercial indicam ainda que produzir nanofibra de celulose com elevado rendimento a partir de um material abundante e barato, e utilizando técnicas simples de processamento é uma estratégia de pesquisa promissora, uma vez que NFCs são amplamente utilizadas na literatura como reforço de matrizes poliméricas e cerâmicas para as mais distintas aplicações.

Os compósitos e o material referência BCP100 apresentaram aspecto homogêneo entre as fases constituintes, indicando que não houve segregação macroscópica dos pós após mistura. A mudança de tonalidade após o tratamento térmico dos compósitos sugere a existência de algum processo termo-oxidativo, que necessita de estudos mais aprofundados para o esclarecimento, uma vez que as NFC puras não se degradam à temperatura a que foram submetidas. Qualitativamente, ao ser quebrado com as mãos, o compósito com maior teor de NFC, mesmo com menor espessura, foi mais resistente à quebra; sugerindo que as nanofibras foram eficientes como carga de reforço mecânico. Entretanto, faz-se necessário 
um protocolo de preparo das pastilhas que assegure dimensões semelhantes em todas as amostras, e ensaios quantitativos para avaliar a eficiência do reforço mecânico.

As análises de espectroscopia de infravermelho sugerem a interação entre as fases constituintes dos compósitos, que apresentaram bandas de transmitância características de ambas as fases, e se tornando mais próximas às da nanofibra à medida que se aumenta o teor dessa fase no compósito. Além disso, a partir de análises de microscopia eletrônica de varredura foi possível observar que os compósitos possuem irregularidades superficiais e poros micrométricos. Essa característica é importante porque tais irregularidades favorecem a fixação de células, e possível colonização do enxerto (TEIXEIRA et al, 2010; GARAI; SINHA, 2017).

A área superficial do compósito BCP75 apresentou um aumento de 158\% em relação ao BCP100. Contrariamente, ao se adicionar mais NFCs, compósito BCP60, ocorreu uma redução de $87 \%$ da área superficial em relação ao BCP100. Infere-se, portanto, que a adição de $25 \%$ de NFC, material com elevada área superficial, aumenta essa propriedade no compósito. A adição de $40 \%$, no entanto, gera o efeito contrário devido ao alto potencial de aglomeração das fibras. Reforçando esse resultado, tem-se que o diâmetro das partículas de BCP60 é maior do que as de BCP75, como pode ser visualizado nas imagens de microscopia eletrônica de varredura.

Os materiais produzidos apresentaram hiperhidrofilicidade, característica interessante para materiais com potencial aplicação como enxerto, pois permite mais facilmente a aproximação do fluido da matriz extracelular, facilitando as interações com o meio biológico. Desta forma, os compósitos de fosfato de cálcio bifásico e nanofibras de celulose, apresentaram-se materiais promissores para aplicação como enxerto em engenharia de tecidos ósseos.

\section{REFERÊNCIAS}

ALBAYRAK, O. Structural and mechanical characterization of boron doped biphasic calcium phosphate produced by wet chemical method and subsequent thermal treatment. Materials characterization, [S.1.], v. 113, p. 82-89, Mar. 2016.

ALBERTS, B. et al. Tecidos Especializados, Células-tronco e Renovação de Tecidos. In: ALBERTS, B. et al. Biologia Molecular da Célula. 5. ed. Porto Alegre: Artmed, 2009. cap. 23. p. 1417-1484.

AZHA.PERIASAMY et al. Vibrational studies of $\mathrm{Na}_{2} \mathrm{SO}_{4}, \mathrm{~K}_{2} \mathrm{SO}_{4}, \mathrm{NaHSO}_{4}$ and $\mathrm{KHSO}_{4}$ crystals. Rasayan J. Chem., Coimbatore, v. 2, n. 4, p.981-989, Jan. 2009.

BOSE, S. et al. Recent advances in bone tissue enbineering scaffolds. Trends In Biotechnology, Pallman, v. 30, n. 10, p.546-554, Oct. 2012. 
CHEN, L et al. Highly thermal-stable and functional cellulose nanocrystals and nanofibrils produced using fully recyclable organic acids. Green Chemistry, [S.1], v.18, n.13, p.3835-3843, Apr. 2016.

ERGUN, C. et al. Synthesis and micostructural characterization of nano-size calcium phosphates with different stoichiometry. Ceramics International. [S.1.], v. 37, n. 3, p. 971-977. Apr. 2011.

FLAMÍNIO, L. N.; PARDINI, L. C. Compósitos e Tecnologia. São Paulo: Edgard Blucher, 2006, 313 p.

FRANÇA, R. et al. Nanoscale surface characterization of biphasic calcium phosphate, with comparisons to calcium hydroxyapatite and $\beta$-tricalcium phosphate bioceramics. Journal of colloid and interface science, [S.1.], v. 420, p. 182-188, Jan. 2014.

FREITAS, G. P. et al. Potential of osteoblastic cells derived from bone marrow and adipose tissue associated with a polymer/ceramic composite to repair bone tissue. Calcified Tissue International, [S.1.], v. 101, n. 3, p.312-320, Apr. 2017.

GUASTALDI, A. C.; APARECIDA, A. H. Fosfatos de cálcio de interesse biológico: importância como biomateriais, propriedades e métodos de obtenção de recobrimentos. Química Nova. Araraquara, v. 33, n. 6, p. 1352-1358, mai. 2010.

GARAI, S.; SINHA, A. Three dimensional biphasic calcium phosphate nanocomposites for load bearing bioactive bone grafts. Materials Science And Engineering: C, [S.1.], v. 59, p.375-383, Feb. 2016.

LIN, Ning; DUFRESNE, Alain. Nanocellulose in biomedicine: current status and future prospect. European polymer journal, [S.L.], v. 59, p. 302-325, ago. 2014.

MARTINS, Maria Alice, et al. Extraction and characterization of cellulose whiskers from commercial cotton fibers. Journal of Materials Science [S.1.], v.46, n. 24, p.78587864, Dec. 2011.

MORAES, A. S. et al. Caracterização morfológica de nanocristais de celulose por microscopia de força atômica: Morphological characterization os cellulose nanocrystals by atomic force microscopy. Revista Matéria, Sorocaba, v. 21, n. 2, p.532-540, jan. 2016.

NAKASHIMA, K. et al. The crystalline phase of cellulose changes under developmental control in a marine chordate. Cellular and Molecular Life Sciences, [S.L], p. 16231631, out. 2010.

NASCIMENTO, P. et al. Nanocellulose produced from rice hulls and its effect on the properties of biodegradable starch films. Mat. Res., [S.1.], v. 19, n. 1, p.167-174, Feb. 2016.

NIKČEVIĆ, I. et al. The Formation and characterization of nanocrystalline phases by mechanical milling of biphasic calcium phosphate/poly-L-Lactide biocomposite. Materials Transactions, [S.1], v. 47, n. 12, p. 2980-2986, Dec. 2006.

NOORI, A et al. A review of fibrin and fibrin composites for bone tissue engineering. International Journal od Nanomedicine, [S.1], v. 12, n. 8, p. 4937-4961, July. 2017.

PETERSON, L. J. et al. Reparação das Feridas. In: PETERSON, L. J. et al. Cirurgia Oral e Maxilofacial Contemporânea. 4. ed. Rio de Janeiro: Elsevier, 2004. cap. 4. p. 55-62.

RAMEZANI, S. et al. Synthesis, characterization and in vitro behavior of nanostructured diopside/biphasic calcium phosphate scaffolds. Materials chemistry and physics, [S.1.], v. 186, p. 415-425, Jan. 2017. 
RAO, K. M. et al. Polysaccharide based bionanocomposite hydrogels reinforced with cellulose nanocrystals: drug release and biocompatibility analyses. International journal of biological macromolecules, [S.1.], v. 101, p. 165-171, Mar. 2017.

SALAMA, Ahmed. Carboxymethyl cellulose-g-poly (acrylic acid)/calcium phosphate composite as a multifunctional hydrogel material. Materials Letters, [S.1.], v. 157, p.243247, Oct. 2015.

SEO, S. et al. Strategies for osteochondral repair: Focus on scaffolds. Journal Of Tissue Engineering, Cheonan, v. 5, p.1-14, July. 2014.

SOLOMONS, T.W.Graham; FRYHLE, Craig B.. Química orgânica. 7 ed. Rio de Janeiro: LTC, 2002. 468 p.

STEIN, R. S. Estudo comparativo da neoformação óssea utilizando-se o enxerto autógeno e três substitutos - defeitos ósseos em ratos. 2009. 59 f. Dissertação (Mestrado) - Pontifícia Universidade Católica do Rio Grande do Sul, Porto Alegre, RS, 2009.

TAIPINA, M. O. Nanocristais de celulose: obtenção, caracterização e modificação de superfície. 2012. 116 f. Dissertação (Mestrado em Química) - Universidade Estadual de Campinas, Campinas, SP, 2012.

TEIXEIRA, E. M. et al. Nanofibras de algodão obtidas sob diferentes condições de hidrólise ácida. Polímeros, São Carlos, v. 20, n. 4, p.264-268, nov. 2010.

TORTORA, G. J.; DERRICKSO, B. O Sistema Esquelético. In: TORTORA, G. J.; DERRICKSO, B. Corpo Humano: Fundamentos de Anatomia e Fisiologia. 8. ed. Porto Alegre: Artmed, 2012. cap. 6. p. 118-163.

UNABIA, R. et al. Synthesis and characterization of nanocrystalline hydroxyapatite and biphasic calcium phosphate using $\mathrm{Ca}(\mathrm{OH})_{2}$ and $\left(\mathrm{NH}_{4}\right) \mathrm{H}_{2} \mathrm{PO}_{4}$. Physica status solidi c, [S.1.], v. 12, n. 6, p. 572-575, June. 2015.

VILLALÁ, M. A. G. et al. Synthesis, chemical and microstructural characterization of micro macroporous biphasic calcium phosphate granules. X-ray spectrometry, [S.1.], v. 46, n. 4, p. 237-241, July. 2017.

YAN, W. et al. In vitro investigation of nanohydroxyapatite/poly(l-lactic acid) spindle composites used for bone tissue engineering. Journal Of Materials Science: Materials in Medicine, [s.L.], v. 27, n. 8, p.2-7, July. 2016. 